\title{
Os sentidos de divulgação científica nas teses e dissertações brasileiras: mapeamento inicial
}

\author{
Natália Martins Flores \\ Doutora; Universidade Federal de Santa Maria, Santa Maria, RS, Brasil \\ nataliflores@gmail.com
}

\section{Maria Ivete Trevisan Fossá}

Doutora; Universidade Federal de Santa Maria, Santa Maria, RS, Brasil fossa@terra.com.br

\section{Resumo}

Apresenta uma análise de sentidos sobre divulgação científica (DC) em teses e dissertações brasileiras sobre o tema. Empreende-se um mapeamento inicial dos trabalhos, com a descrição das áreas de pesquisa e referências bibliográficas de seis teses e 44 dissertações. Partindo-se da perspectiva teórica das teorias da linguagem e do discurso e dos conceitos de memória discursiva e interdiscurso, analisam-se os sentidos sobre DC dos resumos de dez trabalhos. Os estudos mapeados são de variadas áreas científicas, reforçando a DC como um objeto transdisciplinar. Os sentidos de DC alinham-se aos universos de: (1) imagem institucional de universidades e centros de pesquisa; (2) educação científica formal e informal; (3) espaços interativos, transitando entre sentidos tecnicistas, participativos e reflexivos. Assinala-se a validade da metodologia de análise de discurso para se investigar as historicidades de conceitos científicos.

\section{Palavras-chave}

Produção de sentidos. Divulgação científica. Análise de discurso.

\section{Introdução}

A divulgação científica (DC) é apropriada como objeto de pesquisa de cursos de PósGraduação Nacionais, o que mostra uma preocupação crescente em se estudar as relações entre comunicação, ciência e sociedade. Esse interesse reflete-se na produção científica 
desses programas e nas teses e dissertações que eles põem em circulação. Somente entre 2014 e 2016, foram 641 trabalhos científicos dessa ordem produzidos em âmbito nacional, cujos temas abordam a Divulgação Científica, Educação e Ciência, Comunicação, Tecnologia, Ciência e Sociedade, Comunicação Pública da Ciência, Ciência e Sociedade, Popularização da Ciência e Jornalismo Científico (ZANVETTOR; CALDAS, 2016).

A natureza multidisciplinar dos estudos de DC e sua dispersão em diferentes disciplinas torna a sua sistematização uma empreitada difícil e necessária. Uma das iniciativas que se lançam nesse sentido é o projeto de pesquisa de Graça Caldas e Zanvettor (2014) que traçou um Estado da Arte da pesquisa de Divulgação Científica no Brasil. Num segundo momento, a pesquisa mapeou os trabalhos de DC desenvolvidos nas Universidades de São Paulo por meio da Análise de Conteúdo, identificando as áreas de saber, instituições, linhas de pesquisa, temas abordados, metodologias e referenciais teóricos abordados (ZANVETTOR; CALDAS, 2016).

Apesar de ser referência para os estudos de Estado da Arte de DC, a pesquisa de Caldas e Zanvettor (2014) não trata do modo como o conceito é apropriado pelas diferentes áreas de pesquisa mapeadas. As reflexões das teorias do discurso podem auxiliar nessa problematização, ao pensar os conceitos científicos como objetos discursivos construídos por comunidades específicas de cientistas, que sofrem variações e transformações de acordo com sua comunidade discursiva de apropriação. Abre-se espaço para se estudar a construção do conceito de divulgação científica, moldado por olhares de diferentes disciplinas.

Este artigo procura avançar nessas reflexões ao apresentar uma análise da produção de sentidos sobre DC nos trabalhos científicos sobre o tema. Trata-se de uma proposta de operacionalização da análise do discurso como metodologia para se pensar a construção de sentidos no campo científico. Ela é fruto de um projeto de pesquisa que tem o objetivo de problematizar as enunciações sobre DC produzidas pelo campo científico, por cientistas e instituições científicas. Os objetivos específicos se focariam em:

a) analisar a produção de sentidos sobre DC em blogs, falas de cientistas, documentos institucionais e teses e dissertações;

b) e mapear a historicidade desses sentidos, colocando-os em relação com os já ditos em contextos anteriores.

Tendo em conta esses objetivos, nos focamos neste artigo na análise da produção de sentidos nas teses e dissertações sobre DC. Para selecionar o nosso corpus de análise, 
consideramos necessário esboçar um mapeamento de trabalhos científicos sobre DC. Por meio da pesquisa no Banco de Teses e Dissertações da Capes, localizamos 50 trabalhos científicos sobre DC - 44 dissertações e seis teses - publicados no período de 2013-2015. Apresentamos uma descrição sumária das suas áreas de pesquisa e referências bibliográficas na primeira seção do artigo. Desse levantamento, selecionamos dez trabalhos para realizar uma análise de sentidos sobre DC dos seus resumos (abstracts). Trabalhamos com a perspectiva teórica dos estudos do discurso e da linguagem sobre produção de sentidos (BAKHTIN, 2010; ORLANDI, 2002), além de utilizarmos o conceito de memória discursiva, da Análise do Discurso (COURTINE, 1981; PAVEAU, 2006, 2013). Por meio do desvelamento de alguns sentidos circulantes sobre DC, refletimos sobre a natureza das relações entre ciência e sociedade implicados nesse processo.

\section{Discurso científico e produção de sentidos}

As problematizações sobre os sentidos de divulgação científica no campo científico do nosso projeto de pesquisa partem do princípio de que os conceitos científicos são formas de representação da realidade construídas por meio da linguagem por comunidades científicas específicas. Essa perspectiva advém das teorias do discurso e encontra inspiração nas reflexões de Foucault (1971) sobre a formação das ciências ocidentais contemporâneas. O pesquisador traz contribuições para se refletir sobre as ciências como construções sociais formadas não por uma linearidade progressiva de acumulação do conhecimento científico, mas sim pelas técnicas científicas e demarcação de olhares sobre os objetos analisados. Os conceitos científicos são concebidos como estruturas construídas em determinado contexto que sofrem modificações de acordo com a sua trajetória histórica e social.

A abordagem discursiva adotada ajuda-nos a reforçar a ideia que as relações entre coisas - objetos do que se fala - e linguagem são historicamente constituídas (FOUCAULT, 1966), de que não existe uma relação direta entre linguagem/pensamento/mundo (ORLANDI, 2002). Os estudos do discurso tentam mostrar que as produções de sentido e representações de mundo dependem dos seus usos concretos. Essa concepção aparece, por exemplo, nas reflexões bakhtinianas sobre a palavra, vista como um signo neutro e ideológico por excelência, que adquire novas significações de acordo com o seu contexto histórico e a situação imediata de comunicação na qual é utilizada (BAKHTIN, 2010). Vistos 
por esse ângulo, os conceitos e objetos científicos não são estanques e únicos, mas transformam-se num movimento incessante de ressignificações.

As ressignificações conceituais aparecem de forma mais explícita em objetos apropriados por diferentes disciplinas científicas, como é o caso da DC. No contexto da academia, a atividade foi teorizada por comunidades discursivas de pesquisadores de disciplinas pertencentes a distintas áreas de conhecimento, como as Ciências Sociais e Humanas, as Ciências Naturais e Exatas, além de áreas interdisciplinares. Cada uma dessas comunidades constrói olhares específicos sobre a DC, que também se transformam no decorrer da trajetória de pesquisa destas áreas. Torna-se interessante investigar como se dá a construção de sentidos sobre DC nesses discursos científicos.

\section{Recorte dos estudos sobre divulgação científica}

Realizamos um levantamento das teses e dissertações sobre DC que serve de base para extração do corpus de análise do artigo. Por meio do uso da palavra-chave "divulgação científica" no sistema de buscas do Banco de Teses e Dissertações da Capes, localizamos 44 dissertações e seis teses publicadas no período de 2013-2016. A escolha de se utilizar uma palavra-chave se deve a uma tentativa de restringir os sentidos de DC à forma de nomeação/referência mais recorrente nos trabalhos sobre o tema na plataforma (ZANVETTOR; CALDAS, 2016) ${ }^{1}$. Trata-se de um recorte desse campo de estudos que não tem pretensões de ser exaustivo ou quantitativamente representativo.

Os 50 trabalhos sobre DC são das áreas científicas de: Divulgação Científica e Cultural, Educação e Ensino em Ciências, Educação, Linguagem, Ciências, Tecnologia e Sociedade, Comunicação e Informação, Ciências e Biotecnologia, Planejamento e Desenvolvimento Social, Astronomia, Museologia e Patrimônio, Antropologia Social e Química. No Gráfico 1 apresentamos a quantidade de trabalhos mapeados em cada área de conhecimento:

\footnotetext{
1 De acordo com a pesquisa por termos empreendida de janeiro de 2014 a janeiro de 2016, de Zanvettor e Caldas (2016), 27\% dos trabalhos sobre o tema da plataforma Capes de utilizam o termo "divulgação científica", contabilizando 174 de um total de 641 trabalhos. Outros termos que servem para nomear a atividade, como "popularização da ciência" e "jornalismo científico" aparecem, respectivamente, em $12 \%$ e $3 \%$ dos trabalhos deste período.
} 
Gráfico 1 - Quantidade de trabalhos de DC por área de conhecimento

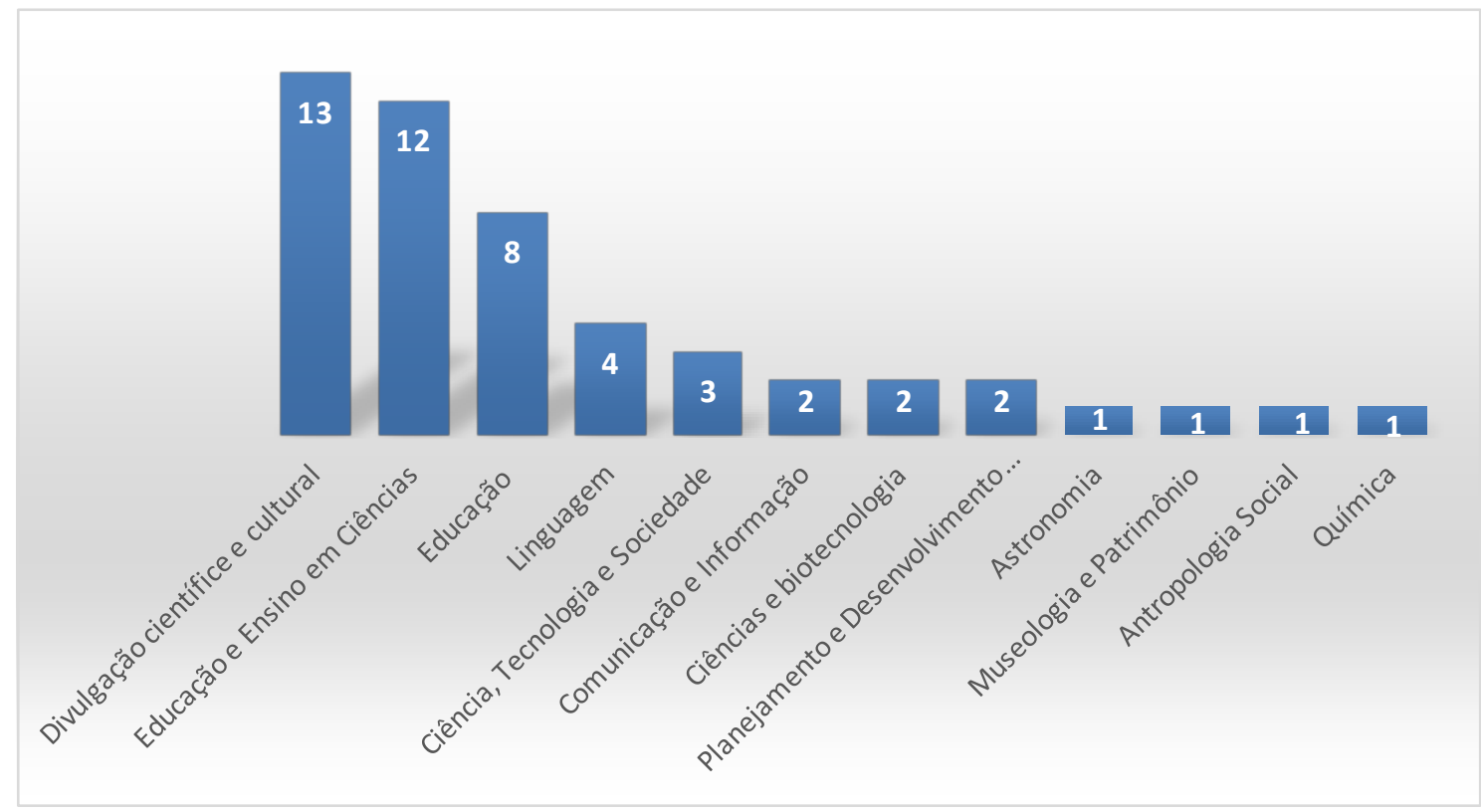

Fonte: Elaborado pelas autoras.

Como podemos observar no gráfico, as áreas de Divulgação Científica e Cultural e de Educação e Ensino em Ciências, que representam, respectivamente, os Programas de PósGraduação interdisciplinares da Unicamp e da Universidade do Estado do Amazonas, concentram a maior quantidade de teses e dissertações por área com, respectivamente, 13 e 12 trabalhos. Esses programas têm a educação e a divulgação científica como eixos temáticos, o que explica a ampla concentração de trabalhos, se comparados a programas restritos a apenas uma disciplina. 0 levantamento corrobora o número significativo de teses e dissertações em Programas interdisciplinares de Pós-Graduação sobre DC, fruto do investimento nessas áreas nos últimos anos. De acordo com Caldas e Zanvettor (2014), apenas no período de 2010-2014, 48 dissertações foram defendidas no Programa de PósGraduação em Divulgação Científica e Cultural, da Unicamp.

Segundo o mapeamento de Zanvettor e Caldas (2016), as Universidades do Estado de São Paulo que mais produzem sobre a temática da DC são as que possuem programas de Pós-Graduação Interdisciplinares com conexão ou que fazem interface com a área de DC. Com exceção da USP e da Metodista, as instituições Unicamp, Unesp, UFSCar e PUC-São Paulo possuem um perfil interdisciplinar. A temática da DC vem sendo tematizada e debatida por áreas interdisciplinares em detrimento de áreas da Comunicação, que foram pioneiros nesses estudos (ZANVETTOR; CALDAS, 2016). 
O mapeamento das referências bibliográficas permitiu identificarmos onze autores de DC mais citados e compartilhados pelos 50 trabalhos (gráfico 2).

Gráfico 2 - Autores de DC mais citados nos trabalhos

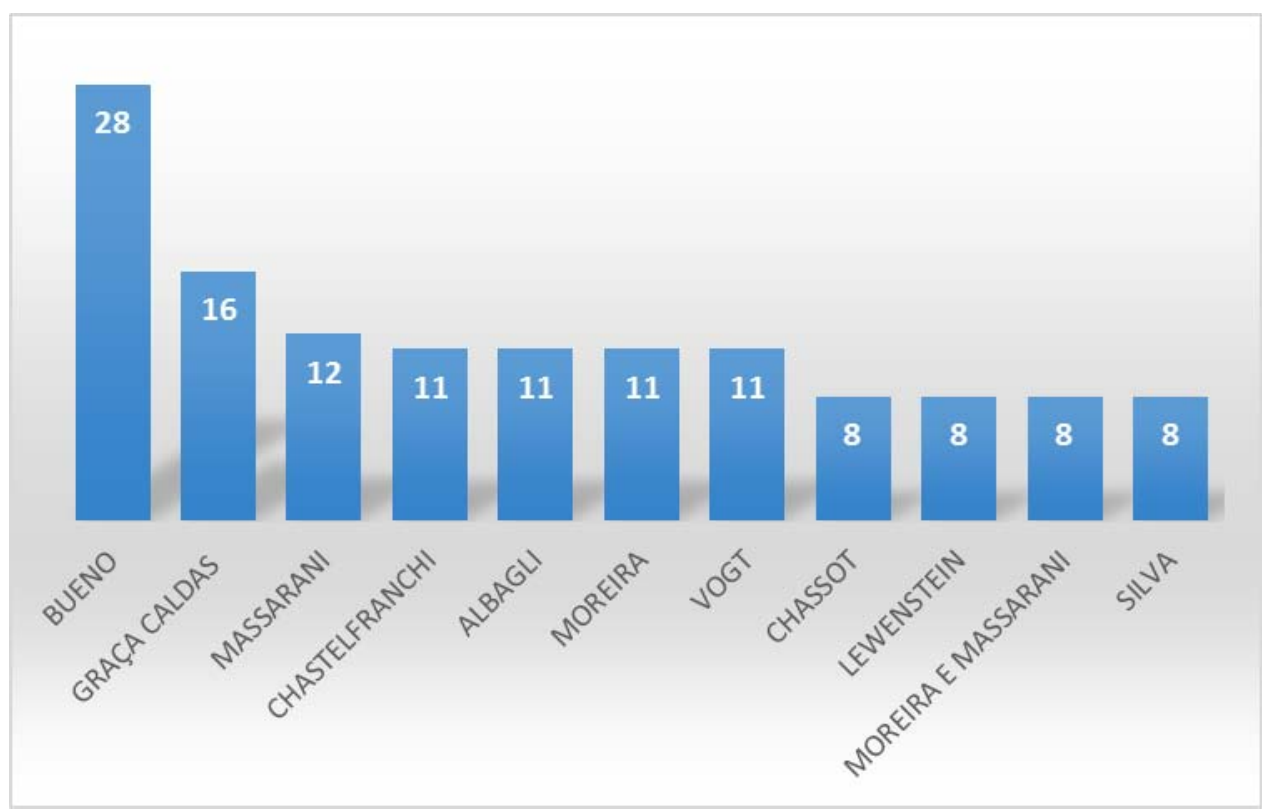

Fonte: Elaborado pelas autoras.

A maioria dos trabalhos não compartilha das mesmas referências bibliográficas. Dos autores mais citados, vemos a predominância de autores como Bueno (2009, 2010, 1972, 1988, 1984, 1985), em 28 trabalhos, Graça Caldas (2005, 2010, 2011), em 16 trabalhos, e Massarani (2013, 2010, 2008, 1988), em 12 trabalhos. Bueno é um dos primeiros pesquisadores brasileiros a conceituar e diferenciar as atividades de divulgação científica, comunicação científica e disseminação científica, o que explica a grande quantidade de teses e dissertações que o trazem como referência. Graça Caldas e Massarani possuem uma trajetória e grupos de pesquisa na Unicamp e na Fundação Oswaldo Cruz já consolidados, o que reflete na significativa disseminação de suas produções na área. Assim também ocorre com outros autores como Castelfranchi $(2008,2009,2010)$ e Vogt $(2003,2006)$, que pesquisam a DC há anos e consolidaram suas identidades em torno dessa temática.

Nossos dados mostram que a maioria dos autores das referências bibliográficas utilizadas pelos estudos mapeados são brasileiros. Das 14 referências mais citadas, apenas uma é de um autor estrangeiro (Lewenstein, citado por oito trabalhos). Isso pode indicar que existe a consolidação de um campo de estudos de DC autônomo de referências e 
bibliografias estrangeiras. Esses apontamentos, no entanto, constituem apenas indícios que precisam ser melhor investigados por meio de mapeamentos quantitativos das teses e dissertações sobre o tema.

\section{Os sentidos de DC em teses e dissertações}

O levantamento possibilitou construirmos um corpus de 10 trabalhos para realizar a análise discursiva de seus resumos. Esse recorte foi feito levando-se em consideração a área de pesquisa dos 50 trabalhos mapeados. Procuramos selecionar trabalhos de distintas áreas de modo que o corpus abarcasse a diversidade de disciplinas encontradas no nosso mapeamento. Outro critério utilizado, de uma matriz qualitativa, levou em conta o modo como o conceito de DC foi desenvolvido nos resumos dos trabalhos. Neste sentido, selecionamos resumos que explicitassem, mesmo que de forma sumária, uma definição/descrição da noção/atividade de DC. As marcas discursivas de definição do conceito serviriam como índices das concepções/matrizes de DC presentes nos estudos específicos.

Nosso corpus é composto de dissertações e teses das áreas de Divulgação Científica e Cultural (3), Educação em Ciências (1), Gestão Social e Desenvolvimento Local (1), Química (1), Comunicação (1), Gestão da Informação (1), Planejamento e Desenvolvimento Regional (1), Ciência, Tecnologia e Sociedade (1) ${ }^{2}$. Como podemos observar, predominam teses e dissertações de programas Interdisciplinares, com um total de sete resumos. Demos preferência aos resumos que discorrem sobre a DC na parte de contextualização e apresentação da problemática de pesquisa, pois esses permitem delinear o conceito de modo mais denso.

Utilizamos o aporte teórico da Análise do Discurso como um gesto de interpretação (ORLANDI, 2002) e os conceitos de interdiscurso e memória discursiva. Escolhemos trabalhar esses conceitos a partir de Jean Jacques Courtine (1981), responsável por propor o conceito de memória discursiva, e de Marie-Anne Paveau (2006), que o trabalha à luz das teorias da cognição social ${ }^{3}$. Nos dois casos, trata-se de formas de observação dos processos

\footnotetext{
2 As áreas de Gestão Social e Desenvolvimento Local e Gestão da Informação constituem-se em mestrados profissionais, enquanto as outras áreas são de Mestrado Acadêmico.

3 Reconhecemos que os conceitos de interdiscurso e memória discursiva possuem uma trajetória de apropriações dentro do campo da Análise do Discurso de linha francesa, como mostra Paveau (2013). No entanto, decidimos focar-nos nas formulações de Courtine (1981) e, posteriormente, de Paveau (2006) por considerarmos que eles dão direcionamentos importantes para pensarmos na operacionalização deste conceito, levando em conta a perspectiva histórica, de um lado, e a cognitiva, de outro.
} 
de construção de sentidos que, a nosso ver, podem ser facilmente operatórios em materialidades empíricas.

Em Courtine (1981), o conceito de memória discursiva serve para articular a produção discursiva ao fio histórico da constituição de sentidos - colocando o discurso na relação com sua história. Por meio da sua formulação, o pesquisador operacionaliza as relações entre o intradiscurso - as marcas textuais discursivas da materialidade - e os discursos anteriores. Por esse viés, analisar a produção de sentidos de determinada materialidade remete em articular o eixo horizontal do discurso concreto e visível (nível da formulação) ao eixo vertical da memória, matriz discursiva de sentido (nível do enunciado). Neste sentido, o modo de existência dos enunciados está sempre em relação ao interdiscurso, ou seja, às reformulações, reiterações e atualizações de enunciados anteriores que operam no nível do discurso (COURTINE, 1981).

Base de todo enunciado, a memória discursiva seria um "saber discursivo que torna possível todo dizer e que retorna sob a forma do pré-construído, o já-dito que está na base do dizível, sustentando cada tomada da palavra" (ORLANDI, 2002, p.31). Paveau (2006) propõe observar essa memória a partir da visão cognitiva, concebendo-a como um elemento formado por meio da imbricação entre as representações e conhecimentos individuais e representações externas e enquadres de saber partilhados socialmente. Sob essa ótica, os enunciados de trabalhos de DC se constituiriam sempre em um jogo com o pré-construído e redes de memória sobre essa prática social, atualizando fragmentos e ditos anteriores.

A operacionalização do conceito de memória discursiva na análise do corpus possibilitou mapearmos redes de memória e universos discursos específicos aos quais os 10 resumos remetem. Esses referem-se a:

a) imagem institucional de universidades e centros de pesquisa (cinco trabalhos);

b) educação científica formal e informal (três trabalhos);

c) e espaços interativos (dois trabalhos).

Eles constituem-se de acordo com os objetos de pesquisa, os enunciadores e o contexto de divulgação científica estudados. Eles também acionam memórias discursivas distintas sobre DC, ora recuperando enunciados que produzem sentidos tecnicistas e pragmáticos sobre a atividade, ora atualizando essas formulações, trazendo enunciados de uma visada construcionista. A seguir discorremos sobre essas construções discursivas e o modo como elas atuam na produção de sentidos sobre DC. 


\subsection{As instituições científicas como agentes de DC}

Os cinco trabalhos do universo da política universitária e institucional centram-se no papel das Universidades e Centros de Pesquisa na conformação de políticas e atividades de DC. O R1 trata da popularização da ciência do Ministério da Ciência, Tecnologia e Inovação e suas 13 unidades de pesquisa, o R2 analisa as atividades de DC de cinco institutos Nacionais de Ciência e Tecnologia sediados na UFMG, o R3 analisa a atuação das Universidades do Grande ABC, o R4 centra-se na análise do uso das redes sociais feitos por Bibliotecas Universitárias Federais do sul do Brasil, enquanto o R5 centra-se na análise do site do Programa de Pós-graduação em Educação e Ensino de Ciências na Amazônia da Universidade do Estado do Amazonas (PPGCEEC/UEA) como canal de divulgação científica.

Os trabalhos dessa vertente resgatam sentidos de DC que vinculam a atividade ao papel social de instituições públicas de ciência. Essa projeção está atrelada a uma rede de memória formada em duas instâncias concomitantes: na sociedade brasileira e no discurso acadêmico. No âmbito da sociedade brasileira, as práticas de políticas públicas e institucionais produzem sentidos sobre a função social das universidades, os lugares sociais dos cientistas e as relações entre ciência e sociedade, que reverberam em sentidos sobre a DC. No âmbito do discurso acadêmico sobre DC, as dissertações, teses, artigos e palestras que tematizam a atividade servem como matrizes discursivas de sentidos para estudos posteriores.

As matrizes de produção de sentidos dessas duas instâncias funcionam como prédiscursos que ajudam a moldar interpretações e significados da atividade. Em Paveau, os pré-discursos são definidos como:

São enquadres de saber, de crenças e de prática que não estão disponíveis apenas no espírito dos indivíduos e na cultura dos grupos (é sua natureza representacional), mas estão distribuídos, no sentido cognitivo do termo, nos ambientes materiais da produção discursiva (PAVEAU, 2013, p. 149).

Pensar nos pré-discursos da DC significa interpretá-los como enquadres tácitos construídos e partilhados socialmente sobre a atividade. Antes de terem uma existência discursiva, esses elementos são implícitos e seriam resgatados e acionados nos discursos sobre DC. Esse processo de acionamento seria destravado, principalmente, pela recorrência aos dispositivos de sedimentação desta memória sobre o papel social da universidade. Os gêneros científicos constituiriam esses lugares de memória para o discurso sobre DC. Já no 
âmbito social esses pré-discursos estariam dispersos nas memórias individuais e coletivas sobre as relações entre ciência e sociedade.

As redes de memória operam uma demarcação do espaço social e discursivo das universidades e das instituições públicas como agentes no processo de DC. Essa posição está relacionada à memória histórica brasileira de responsabilização do setor público na propulsão da cultura científica no país, impulsionada pelo projeto nacionalista da ditadura militar, nas décadas de 70-80. Esse projeto consistia em um resgate do espírito desenvolvimentista do contexto pós-Segunda Guerra Mundial, no qual houve uma maior articulação da comunidade científica já existente desde 1920 (MOREIRA, MASSARANI, 2002), que culminou na criação do CNPq, em 1951. Demarcaram-se, então, políticas públicas de CT\&I, que foram reatualizadas nos governos do Partido dos Trabalhadores (anos 2000). Por meio desses pré-discursos, a DC é concebida como uma responsabilidade social das instituições públicas.

No corpus, moldam-se enunciados em que as instituições de pesquisa figuram como agentes centrais nos processos de DC. As universidades aparecem como lugares de origem do conhecimento científico e, por essa razão, responsáveis pela sua disseminação na sociedade. Essas instituições são "geradoras de conhecimento e propulsoras de pesquisa", que, por isso, "tem importante papel na divulgação científica e fortalecimento desta cultura" (Exemplo 1, R3). No R1, as universidades são colocadas numa posição de "gestoras das ações de pesquisa e desenvolvimento do Sistema de CT\&I brasileiro" e de "geradoras e difusoras de conhecimento de ponta em benefício da sociedade" (Exemplo 2). Nesse último exemplo, se articulam também redes de memória que justificam a importância das atividades científicas para os indivíduos sociais. A instituição científica é alçada à posição de benfeitora social ao produzir conhecimentos que serão colocados à disposição da sociedade.

Seguindo essa linha, produzem-se sentidos sobre a DC como uma intermediação entre os espaços da instituição científica e da sociedade. Esse sentido liga-se à memória histórica de distanciamento entre a ciência - tida como uma prática hermética e complexa, desenvolvida por poucos iniciados - e a sociedade, lugar dos conhecimentos do senso comum e do leigo. Esses fios discursivos podem ser observados na memória coletiva social e nos discursos acadêmicos sobre a DC. A DC aparece vinculada à supressão da lacuna entre os espaços da ciência e da sociedade e reitera-se por meio de enunciados que a colocam como ponte entre os universos distintos dos cientistas e dos leigos. Essa ponte, no entanto, é apenas simbólica, não propondo a transposição dos limites desses universos sociais. 
No R5, vemos um posicionamento explícito da função da DC como um meio de educar o leigo, definida, em uma sequência discursiva como "uma forma de saber lidar com a impregnação científica da sociedade para aprimorar as oportunidades de desenvolvimento" (Exemplo 3). Esses termos vinculam-se a uma visada desenvolvimentista e tecnicista da divulgação científica que vê na atividade um modo de sanar o fosso existente entre a cultura científica e a cultura do senso comum. Os sentidos remetem à memória histórica iluminista da modernidade e entendem que existe uma relação diretamente proporcional entre uma cultura científica aprimorada e o desenvolvimento social. A ciência é vista como uma forma de emancipação (SANTOS, 2002), e a DC como um meio de democratizar o acesso a esse mundo. Essa construção discursiva torna-se predominante no contexto brasileiro de desigualdade social em que apenas $3 \%$ da população tem acesso aos bancos universitários.

Os sentidos sobre divulgação científica reverberam e são também produzidos pela esfera acadêmica, em trabalhos que teorizam sobre essas práticas. Observa-se que os sentidos que colam a atividade à visada tecnicista e desenvolvimentista caracterizou os estudos sobre DC em uma primeira fase, nomeada de Definição Teórica, cuja preocupação dos pesquisadores voltava-se para o estudo da recodificação/simplificação da linguagem operada por essas práticas (FLORES, GOMES, 2014). O Modelo do Déficit constitui-se em paradigma predominante nesses estudos, que entendiam a DC como a transmissão unidirecional de conhecimentos acabados e encapsulados do cientista para o leigo (tidos como "analfabetos em ciência") (MOREIRA, MASSARANI, 2002). Essa visada encontra consonância também nos modelos de comunicação que a concebiam como um processo de transmissão de informações emissor-receptor, cujo sentido da mensagem era único e fixo (FLORES, GOMES, 2014).

Ainda que não se tenha uma visão totalmente respaldada no Modelo do Déficit visto como um modelo retrógrado por muitos pesquisadores da área - os discursos dos cinco resumos analisados aproximam-se da sua visão linear e tecnicista ao posicionarem a instituição científica como enunciadora central e também ao procurar avaliar a qualidade das atividades de comunicação e divulgação científica. No primeiro caso, tem-se a manutenção do status quo da comunidade científica como mantenedora e gestora do conhecimento científico, legitimada para realizar esse processo, que também lhe dá visibilidade. A avaliação das atividades de DC nas instituições presume a existência de um 
modo "eficaz e efetivo" (R5), abordando a comunicação em um viés mecanicista e não como um processo complexo que envolve outros fatores além da atuação da instituição científica.

\subsection{Os espaços interativos e da educação}

Agrupamos nos universos da educação científica formal e informal e dos espaços interativos os resumos que analisam objetos de DC que circulam na mídia, nas escolas e na internet. Eles caracterizam-se por focarem em outros objetos aquém das ferramentas institucionais de DC, permitindo a entrada de uma visada crítica e reflexiva da atividade, que tenta observar a complexidade de relações entre os agentes sociais que a praticam e seus públicos. Eles atualizam redes de memória relacionadas a uma ampliação das práticas de divulgação científica para espaços informais de educação, como museus científicos e meios de comunicação no geral.

No eixo da educação científica, temos um trabalho que faz uma análise crítica da obra de divulgação científica do astrônomo Carl Sagan (R6) e outro que analisa a alfabetização científica de química desenvolvida com alunos do ensino médio e graduação por meio da produção de Histórias em Quadrinhos (HQs) (R7). Já no eixo do espaço interativo da internet, temos um estudo sobre os espaços de interatividade de DC na web (R8), um segundo sobre os modelos de divulgação científica e internet (R9) e um terceiro sobre a internet como ferramenta para o desenvolvimento da região metropolitana do Vale do Paraíba (R10). Eles convergem na introdução de modos críticos de se pensar a divulgação científica na sua relação com públicos cada vez mais participativos.

As sequências discursivas desses resumos atualizam enunciados que remetem a redes de memória relacionadas ao contexto sócio histórico contemporâneo da sociedade, no qual há modificações educacionais e mercadológicas substanciais, proporcionadas pela popularização das tecnologias digitais da comunicação e da informação. Pensamos, sobretudo, nas relações entre aluno/educador e consumidor/produtor, cujas fronteiras se tornam permeáveis por meio da emergência do que Shirky (2011) nomeia de cultura participativa de inclusão do amador na produção de conteúdo. Esse cenário faz emergir redes de sentido que legitimam as pessoas comuns como participantes ativos dos processos de comunicação. Esses sentidos também transbordam para as práticas de divulgação científica por meio do questionamento das posições estanques de cientista/leigo e por uma consequente inclusão deste último nos processos de produção de DC. 
Nesse caso, as redes de sentido são constituídas por memórias sedimentadas em materialidades de outros campos discursivos - a cultura da participação, as indústrias do entretenimento e as tecnologias digitais de comunicação - apropriadas pelo campo de estudos de DC. Esse processo confronta sentidos e memórias históricas sobre a DC a novos enunciados. As memórias que posicionam os agentes do campo científico como únicos produtores legitimados de DC são colocadas em suspensão em favor de um alargamento do campo de enunciadores e inclusão da pessoa comum como enunciadora legítima dessas produções discursivas.

Os pré-discursos relacionados a essa visada sedimentam-se nos discursos acadêmicos contemporâneos sobre DC, que tematizam as relações entre a atividade e o poder, e também nos discursos sobre ciência pós-moderna, que a concebem como uma construção social. Levy-Leblond (2008) faz parte desse movimento ao mostrar que a separação entre cientista e leigo é apenas um mecanismo artificial de perpetuação do poder e de legitimação da comunidade científica como donos do dizer científico. Nomeada de Fase de Consolidação Crítica e Teórica, esses trabalhos começam a compreender a atividade a partir de uma visão crítica e reflexiva como um processo multidirecional de comunicação (FLORES, GOMES, 2014).

Uma característica marcante de trabalhos que resgatam esses fragmentos discursivos consiste na quebra do monopólio da fala e da divulgação científica do cientista e da instituição científica. Emergem enunciados que questionam os saberes tradicionais desses atores e os sentidos de DC. Vemos essa visada nas marcas discursivas do R6, quando se propõe a fazer uma "análise crítica da obra de divulgação científica do astrônomo estadunidense Carl Sagan". Essa crítica sedimenta-se já nos enunciados de descrição do astrônomo (Exemplo 4):

\begin{abstract}
Cientista e autor multifacetado, largamente conhecido como um dos maiores divulgadores da ciência do século XX, Sagan utilizou os meios de comunicação mais poderosos de seu tempo para divulgar e advogar sua visão pessoal da ciência. Ao mesmo tempo em que buscou tornar o conhecimento científico compreensível e atraente para um vasto público não especializado, Sagan também procurou fazer uma defesa apaixonada da ciência, de seus métodos e de sua visão de mundo (R6).
\end{abstract}

No trecho, o uso das marcas discursivas "sua visão pessoal da ciência" e "uma defesa apaixonada da ciência" atualizam dizeres anteriores que colocam em suspensão a objetividade e a imparcialidade científica. Pensamos, sobretudo, nos enunciados de 
Feyerabend (1977), que afirmam o empreendimento científico como uma construção humana construída por meio de ideias humanas e que, por isso, sofre influências de conhecimentos, como "o preconceito, a vaidade e a paixão" (FEYERABEND, 1977, p. 279), excluídos da ciência moderna. Os enunciados analisados reiteram e atualizam essa matriz discursiva para pensar na DC como uma estratégia de defesa de uma visão de ciência específica.

Outra tendência trazida pela quebra do monopólio do cientista divulgador é a inclusão do público nas atividades de DC. Essa perspectiva pode ser observada nos enunciados do R7, que trabalha a produção de HQs no contexto de alunos de graduação e ensino médio. A relação de quebra do monopólio de fala aparece no modo como o enunciador explica a sua apropriação do conceito de alfabetização científica, deslocando-o do seu sentido do contexto do modelo do déficit. Para ele, o processo de alfabetizar-se cientificamente "compreende não só a ciência em si, mas também é capaz de percebê-la em seu dia a dia e futuramente contribuir como cidadão" (Exemplo 5). Para além da transmissão de informações científicas, os sentidos de DC integram o aluno como cidadão capaz de utilizar os conhecimentos científicos conforme seu contexto social.

A perspectiva crítica e construcionista da DC também se materializa pela escolha do próprio objeto de análise, que impõe questionamentos e reflexões ao campo. Esse é o caso dos resumos R8, R9 e R10, cujas análises centram-se nas potencialidades da internet para divulgar ciência. Vemos surgir sentidos que relacionam a DC à participação, com o uso de marcas discursivas como "cultura científica interativa", "interatividade" (R8) (Exemplo 6). Nos enunciados de R9, o próprio ambiente da internet atua como objeto operador de transformações no modo de se pensar a DC, o que permite à pesquisadora "revisitar e colocar alguns questionamentos sobre a própria noção de 'modelo'" (Exemplo 7) (R9). Abre-se, então, espaços para compreender a DC nas suas transformações conceituais, desvinculadas de uma visada monológica e fechada em modelos preconcebidos.

\section{Considerações finais}

Neste artigo, procuramos empreender uma análise discursiva dos sentidos de DC que circulam no campo científico, por meio do olhar sobre as teses e dissertações brasileiras sobre o tema. Antes de fechar conclusões a partir da exaustão de análise de dados, a análise focou-se em um corpus reduzido como forma de exemplificar a operacionalização dos 
conceitos de memória discursiva e interdiscurso para se pensar a produção de historicidades de sentidos de conceitos científicos. Intentamos mostrar a validade da perspectiva teórico-metodológica da Análise de Discurso para descontruir os sentidos que a ciência faz trabalhar no seu discurso. Trata-se de uma tarefa de desnaturalização do objeto científico e de desestabilização de sentidos que tentam ser intencionalmente apagados pelo discurso científico. A ciência passa a ser enxergada como uma atividade humana, social e historicamente construída e condicionada a erros e acertos.

O conceito de memória discursiva possibilitou mapearmos redes de memória que operam na construção de sentidos sobre DC. Esses sentidos transitam tanto no âmbito social - relacionados a memórias coletivas - quanto no discurso acadêmico, o que mostra que essas esferas se entrecruzam na produção de discursos. Num primeiro movimento, essa historicidade alça a instituição científica como agente legítima das práticas de DC, e faz com que a atividade atue como legitimadora do sistema científico e mantenedora do status quo da ciência. Vemos, também, um movimento de alargamento das fronteiras da atividade, com uma visada mais reflexiva e construcionista e a inclusão de outros atores sociais na sua produção. Para além das marcas discursivas pontuais apontadas nos resumos, salientamos a necessidade de se realizar uma análise mais apurada das estruturas dos trabalhos na sua totalidade para compreender as vicissitudes heterogêneas que perpassam essas materialidades.

Além disso, salientamos também a necessidade de se realizar mapeamentos de sentidos de DC em teses e dissertações de disciplinas específicas, abarcando um período mais extenso de coleta de dados. Esses movimentos poderiam mostrar de modo mais detalhado como os sentidos da atividade transitam e sedimentam-se historicamente na área. Pensamos, particularmente, na área de pesquisa de Comunicação e nos nossos interesses de se pensar como e quais processos comunicativos são instituídos por meio das redes de memória de DC. Empreender uma pesquisa dessa ordem levaria a compreender quais as problemáticas comunicativas e a complexidade das relações entre ciência e sociedade.

\section{Referências}

BAKHTIN, Mikhail. Marxismo e filosofia da linguagem: problemas fundamentais do método sociológico da linguagem. 12. ed. São Paulo: Hucitec, 2010. 
BUENO, Wilson da Costa. Comunicação científica e divulgação científica: aproximações e rupturas conceituais. Revista Informação \& Informação, Londrina, v. 15, n. 1 esp., p. 1-12, 2010.

BUENO, Wilson da Costa. 0 jornalismo científico no Brasil: os desafios de uma longa trajetória. In: PORTO, Cristiane de Magalhães (Org). Difusão e cultura científica: alguns recortes. Salvador: EDUFBA, 2009. p. 113-125

BUENO, Wilson da Costa. Jornalismo Científico no Brasil: aspectos teóricos e práticos. São Paulo: ECA USP, 1988. v. 1.

BUENO, Wilson da Costa. Jornalismo científico: conceito e funções. Ciência e Cultura, Rio de Janeiro, v. 37, n. 9, p. 1420-1421, set. 1985.

BUENO, Wilson da Costa. Jornalismo científico no Brasil: compromissos de uma prática dependente. 1984. Tese (Doutorado em Comunicação) - Escola de Comunicações e Artes, Universidade de São Paulo, São Paulo, 1984.

BUENO, Wilson da Costa. 0 jornalismo como disciplina científica: a contribuição de Otto Groth. São Paulo: ECA USP, 1972.

CALDAS, Maria das Graças; ZANVETTOR, Kátia. 0 estado da arte da pesquisa em divulgação científica no Brasil: apontamentos iniciais. Ação Midiática, Curitiba, n. 7, p. 1-11, 2014.

CALDAS, Maria das Graças. Divulgação científica e relações de poder. Informação \& Informação, Londrina, v. 15, n. 1 esp., p. 31-42, 2010.

CALDAS, Maria das Graças. Mídia, educação científica e cidadania. In: REUNIÃO BIENAL DA REDE PARA A POPULARIZAÇÃO DA CIÊNCIA E DA TECNOLOGIA NA AMÉRICA LATINA E NO CARIBE, 9., 2005, Rio de Janeiro. Atas... Rio de Janeiro, 2005.

CALDAS, Maria das Graças. 0 valor do conhecimento e da divulgação científica para a construção da cidadania. Revista Comunicação e Sociedade, São Paulo, n. 56, p. 9-28, 2011.

CASTELFRANCHI, Yuri. Por que comunicar temas de ciência e tecnologia ao público? (Muitas respostas óbvias... mais uma necessária). In: MASSARANI, Luisa (Org.) Jornalismo e ciência: uma perspectiva ibero-americana. Rio de Janeiro: Fiocruz, 2010. p. 13-21.

CASTELFRANCHI, Yuri. As serpentes e o bastão: tecnociência, neoliberalismo e inexorabilidade. Tese (Doutorado em Sociologia) - Instituto de Filosofia e Ciências Humanas, Universidade Estadual de Campinas, Campinas, 2008.

CASTELFRANCHI, Yuri. Ethos e práticas no funcionamento da tecnociência contemporânea. In: CONGRESSO BRASILEIRO DE SOCIOLOGIA, 14., 2009, Rio de Janeiro. Anais... Rio de Janeiro: Sociedade Brasileira de Sociologia, 2009. 
COURTINE, Jean Jacques. Quelques problèmes théoriques et méthodologiques en analyse du discours, à propos du discours communiste adressé aux chrétiens, Langages, Paris, v. 15, n. 62, p. 9-128, 1981. Número temático "Analyse du discours politique".

FEYERABEND, Paul. Contra o método. Rio de Janeiro: Francisco Alves, 1977.

FLORES, Natália Martins; GOMES, Isaltina. 0 público da divulgação científica no paradigma da cultura participativa. Ação Midiática, Curitiba, n. 7, p. 1-15, 2014.

FOUCAULT, Michel. L’ordre du discours. Paris: Éditions Gallimard, 1971.

FOUCAULT, Michel. Les mots et les choses. Paris: Éditions Gallimard, 1966.

LEVY-LEBLOND, Jean-Marc. (Re) mettre la science em culture: de la crise épistemologique à l'exigence éthique. Courrier de l'environnement de l'INRA, Paris, n. 56, p. 7-16, 2008.

MASSARANI, Luisa. Comunicação da ciência e apropriação social da ciência: algumas reflexões sobre o caso do Brasil. Unipluriversidad, Medellín, v. 12, n. 3, p. 92-100, 2013.

MASSARANI, Luisa. Jornalismo científico no Brasil: um panorama geral e desafios. Salto para o Futuro, Brasília, v. 20, n. 1, p. 22-27, abr. 2010. Divulgação científica e educação.

MASSARANI, Luisa (Org.) Ciência \& criança: a divulgação científica para o público infantojuvenil. Rio de Janeiro: Museu da Vida, 2008.

MASSARANI, Luisa. A divulgação científica no Rio de Janeiro: algumas reflexões sobre a década de 1920. 1988. Dissertação (Mestrado em Ciência da Informação) - Instituto Brasileiro de Informação em Ciência e Tecnologia e Universidade Federal do Rio de Janeiro, Rio de Janeiro, 1988.

MOREIRA, Ildeu; MASSARANI, Luisa. Aspectos históricos da divulgação científica no Brasil. In: MASSARANI, Luisa.; MOREIRA, Ildeu C.; BRITO, Fátima. (Org.). Ciência e público: caminhos da divulgação científica no Brasil. Rio de Janeiro: Casa da Ciência, 2002. p. 43-64.

ORLANDI, Eni. Análise de discurso: princípios e procedimentos. Campinas: Pontes, 2002.

PAVEAU, Marie-Anne. Memória, des-memória, a-memória: quando o discurso volta-se para seu passado. Revista Eletrônica de Estudos Integrados em Discurso e Argumentação EID\&A, Ilheus, n. 5, p. 137-161, dez. 2013.

PAVEAU, Marie-Anne. Les prédiscours. Sens, memoire, cognition. Paris: Presses Sorbonne Nouvelle, 2006.

SANTOS, Boaventura Sousa. A crítica da razão indolente: contra o desperdício da experiência. 4. ed. São Paulo: Cortez, 2002.

SHIRKY, Clay. A cultura da participação: criatividade e generosidade no mundo conectado. Rio de Janeiro: Zahar, 2011. 
VOGT, C. A espiral da cultura científica. Com Ciência, Campinas, n. 45, jul., 2003.

VOGT, Carlos. Ciência, Comunicação e Cultura Científica. In: VOGT, Carlos. (Org.). Cultura científica: desafios . São Paulo: Editora da Universidade de São Paulo, 2006. p. 18-26.

ZANVETTOR, Kátia; CALDAS, Graça. Divulgação científica e interdisciplinaridade. In: CONGRESSO BRASILEIRO DE CIÊNCIAS DA COMUNICAÇÃO, 39., 2016, São Paulo. Anais... São Paulo: Intercom, 2016.

\section{Apêndice A - Dissertações analisadas}

CARMO, Vanessa Aparecida do. A divulgação científica nas universidades do Grande ABC: Inovações ou repetição de formatos? 2015. Dissertação (Mestrado em Comunicação) Programa de Pós-Graduação em Comunicação, Universidade Municipal de São Caetano do Sul, São Caetano do Sul, 2015.

FRANCA, Andressa de Almeida. Divulgação científica no Brasil: espaços de interatividade na Web. 2015. 136f. Dissertação (Mestrado em Ciência, Tecnologia e Sociedade) - Programa de Pós-Graduação em Ciência, Tecnologia e Sociedade, Universidade Federal de São Carlos, São Carlos, São Paulo, 2015.

IWATA, Adriana Yumi. Alfabetização e Divulgação científica de química por meio da produção de histórias em quadrinhos e atividades educativas não-formais. 2015. Dissertação (Mestrado em Química) - Programa de Pós-Graduação em Química, Universidade Federal de São Carlos, São Carlos, 2015.

MARTINS, Jefferson. A divulgação pública da ciência em prol do desenvolvimento da Região Metropolitana do Vale do Paraíba. 2013. Dissertação (Mestrado em Planejamento e Desenvolvimento Regional) - Universidade de Taubaté, Taubaté, 2013.

MATEUS, Wagner de Deus. A divulgação científica na página web do PPGEEC/UEA: contribuições para a educação científica. 2013. Dissertação (Mestrado em Educação de Ciências na Amazônia) - Programa de Pós-Graduação em Educação e Ensino de Ciências na Amazônia, Universidade do Estado do Amazonas, Manaus, 2013.

OLIVEIRA, Isabel Cristina de. Ciência que encanta e [des]encanta: a comunicação científica e os INCTS - Institutos Nacionais de Ciência e Tecnologia. 2013. Dissertação (Mestrado em Gestão Social, Educação e Desenvolvimento Local) - Centro Universitário UNA, Belo Horizonte, 2013.

PEREIRA, Danilo Nogueira. A visão de ciência propagada por Carl Sagan. 2013. Dissertação (Mestrado em Divulgação Científica e Cultural) - Instituto de Estudos da Linguagem, Universidade Estadual de Campinas, Campinas, 2013.

RODRIGUES, Meghie de Sousa. Modelos em divulgação científica e internet no Brasil: que caminhos? 2015. Dissertação (Mestrado em Divulgação Científica e Cultural) Instituto de Estudos da Linguagem, Universidade Estadual de Campinas, Campinas, 2015. 
VEIGA, Ana Paula Soares. Comunicação pública e popularização da ciência: o Ministério da Ciência, Tecnologia e Inovação e suas unidades de pesquisa. 2015. Dissertação (Mestrado em Divulgação Científica e Cultural), Instituto de Estudos da Linguagem, Universidade Estadual de Campinas, Campinas, 2015.

VICENTE, Natali Ilza. 0 uso do Twitter e facebook para divulgação científica: um estudo netnográfico em perfis de bibliotecas universitárias federais do sul do Brasil. 2015.

Dissertação (Mestrado Profissional em Gestão da Informação) - Universidade do Estado de Santa Catarina, Florianópolis, 2015.

\title{
The meanings of Science popularization in Brazilian scientific thesis and dissertations: an initial mapping
}

\begin{abstract}
It presents the analysis of meanings of science popularization in Brazilian thesis and dissertations about the theme. It makes an initial mapping of this material, by the description of the research areas and scientific references of 6 theses and 44 dissertations. The meaning production of science popularization of ten abstracts of these studies are analyzed by the use of the theoretical perspective of language studies and theories of discourse, and the concepts of discursive memory and interdiscourse. The theses and dissertations mapped in this analysis are from various scientific areas, reinforcing the science popularization study as transdisciplinary. The meanings of science popularization of these ten analyzed abstracts align themselves to the universes of: (1) institutional image of universities and research centers; (2) formal and informal science education; (3) interactive spaces. They move themselves between tecnicist, participatory and reflexive meanings. It is noted the validity of discourse analysis methodology to investigate the historicity of scientific concepts.
\end{abstract}

\section{Keywords}

Meaning production. Science popularization. Discourse analysis.

Recebido em 08/03/2017

Aceito em 21/06/2017 